Portland State University

PDXScholar

$1-1-2021$

\title{
Changing Practices for Connected Discourse: Starting and Developing Topics in Conversation
}

John Hellermann

Portland State University, jkh@pdx.edu

Yo-an Lee

Sogang University

Follow this and additional works at: https://pdxscholar.library.pdx.edu/ling_fac

Part of the Applied Linguistics Commons

Let us know how access to this document benefits you.

\section{Citation Details}

Published as: Hellermann, J., \& Lee, Y.-an. (2021). Changing practices for connected discourse: Starting and developing topics in conversation. Journal of Pragmatics, 172, 89-104. https://doi.org/10.1016/ j.pragma.2020.11.007

This Post-Print is brought to you for free and open access. It has been accepted for inclusion in Applied Linguistics Faculty Publications and Presentations by an authorized administrator of PDXScholar. Please contact us if we can make this document more accessible: pdxscholar@pdx.edu. 


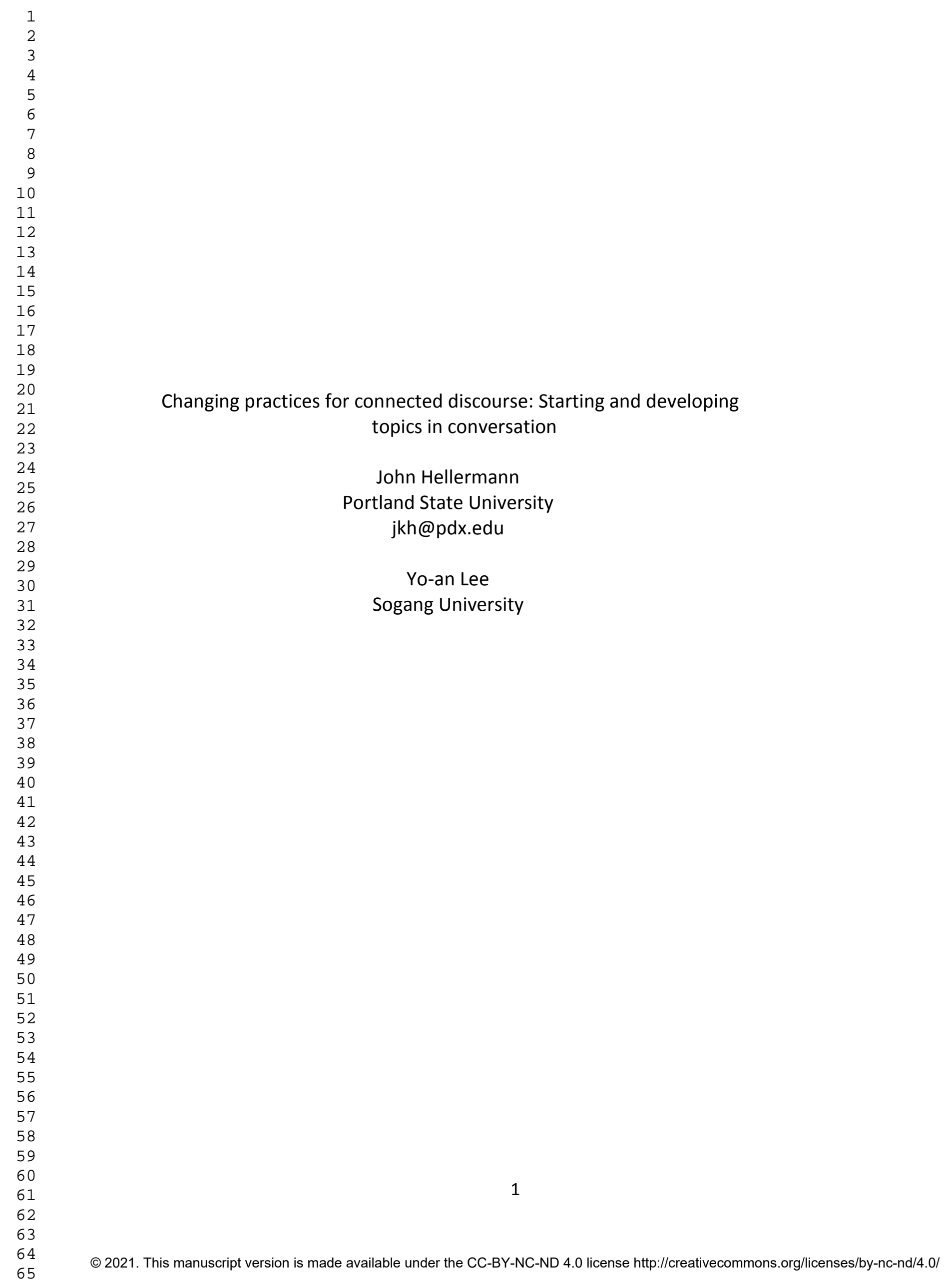




\section{Introduction}

To those unfamiliar with research in ethnomethodological conversation analysis (CA), everyday conversation may seem to be chaotic, unstructured, and incoherent. Research on language use in institutional settings like classrooms or service encounters (Mehan, 1979; Drew \& Heritage, 1992) has uncovered patterned turn taking structures in these goal-oriented settings. In everyday mundane conversation as well, CA research has shown that conversationalists achieve local, situated coherence when they talk. And because mundane conversations are not like the more scripted institutional interactions, there are numerous possibilities and contingencies that participants in conversation must manage (Lee, 2006). One of the more contingent, unplanned, aspects of a conversation, and, possibly, one of the more difficult aspects for a language learner, is how to develop a topic in a face to face conversation ${ }^{1}$.

\subsection{Review of previous research}

\subsection{Topic}

The study of how participants in conversation achieve coherence in their talk started with Sack's observations that participants in a conversation move through topics without always orienting to the moments in which they change from talking about one thing to talking about another (1992, v. 2, p. 352). The ineluctable nature of 'topic' observed by Sacks fostered a long line of research in conversation analysis on the issue including research on the process nature or 'topicality' (Maynard, 1980), topic introductions (Maynard \& Zimmerman, 1984; Button \& Casey, 1984, 1985), different types of topic changes or shifts (Crow, 1983; Jefferson, 1984; Sacks, 1992 (on stepwise topic shift), and closing topics (Holt, 2010). This research has shown that when sequences of talk are investigated in detail, we see that although 'topic' is not so easily defined by the analyst, participants in interaction connect their turns and content (including introducing, changing, and closing topics) in orderly ways ${ }^{2}$.

\subsection{Getting started}

Research on how the familiarity of conversational participants plays a part in its structure (Maynard \& Zimmerman, 1984; Svennevig, 1999) has shown how unacquainted participants engage in a certain amount of pre-topic talk at the start of their interactions. These participants make inquiries about personal biographies (getting to know one another) before launching into more general conversational topics. Among unacquainted participants, excursions away from the topic are often needed to clarify referents and potentially shared knowledge. Conversely, when participants are acquainted, topics are initiated by reference to shared knowledge or topics. The mention of a common person referent is enough to start topical talk on that referent. Not only does such a reference initiate a topic, it makes visible and reproduces (Maynard \& Zimmerman, p. 313) the identity dispositions of the participants as 'acquaintances'.

\footnotetext{
${ }^{1}$ In this paper, we are not addressing starting interactions in contexts such as telephone conversations (Schegloff, 1968; Arminen \& Leinonen, 2006) or medical consultations (Webb et al 2013) or simple greetings (Pillet Shore, 2012)

${ }^{2}$ Another productive line of research related to topic but that we cannot discuss completely in this paper is the organization of longer conversational projects like story tellings (Jefferson, 1978; Goodwin, 1984; Mandelbaum, 1993; Lee \& Hellermann, 2014).
} 
In another study that focused on getting conversations started, Button \& Casey (1985), discuss the nature of topical talk and two main procedures for initiating conversational topics. In the first, the itemized news inquiry, a participant inquires about something relevant to the particular recipient(s): Did you talk to the florists yet? In proffering this, the inquirer commits to have the recipient do more than provide a simple response (yes or no). And in recognizing the inquiry as a topic proffer, the respondent not only gives a more extended answer, but frames the response in such a way as to make contributions by others relevant on the burgeoning topic. When participants offer an itemized news inquiry, they are showing that there is shared background between themselves and other participants. They are asking the recipient to tell more about something for which there is shared context. All participants, however, may not have the same epistemic access to a matter raised. An inquiry such as how is your foot may be a topic about which both parties know something but it is something to which the recipient, not the inquirer, has more epistemic access (Button \& Casey, 1985).

The second procedure is the news announcement in which the announcer makes a partial report of an activity (speaker has primary epistemic status, recipient is a "knowing third party", Button \& Casey, 1985, p. 22). Such an announcement is designed as partial so that a coparticipant can contribute making the announcement something to be pursued as a topic and not simply a telling by one party.

\subsection{Studies of connected discourse among language learners}

Linguists first attempts at understanding the connected discourse of language learners focused on structural features such as anaphora (Givon, 1978), article use (Young, 1996) and other indexical work of tense and aspect (Bardovi-Harlig, 1998, 2000). These studies used linguistic constructs as their starting points for the investigations. In contrast, studies of language learners that used methods from Conversation Analysis (CA), referred to as CA for SLA, (Markee, 2008) have looked to the research inquiries from CA as their starting point. This means their investigations focus on language learners as participants in social interaction who work to accomplish this interaction in a joint way. These studies have searched for evidence of learning in the practices of topic management. For research on language learners, Pekarek Doehler (2004) was the first to examine the relationship between sequential structure in interaction and discourse structure. Focusing on left and right dislocation in learners of L2 French, the study shows the mutual influence of grammatical structure and the constraints and affordances that arise in interaction.

\subsection{Interactional studies of language learners}

Lee has investigated the more general phenomenon of 'connected discourse' (Lee, 2012, Lah \& Lee, 2015). The author (2012) noted that one of the skills needed for advanced level proficiency in a language is the ability for participants in talk-in-interaction to manage contingencies that arise such as expanding a potentially-complete turn (turn extension, repetition) and using different reporting formats (tellings versus dialogic exchanges). Similarly, in research from a Japanese language classroom, Mori (2002) showed a similar orientation to the contingencies of talk-in-interaction. In preparing for conversations with a native speaker expert, students were given time to plan for their interaction. The planning led to a constricted question-answer structure in their interaction. However, when an answerer solicited the assessment of a questioner or when an assessment was made by a questioner, the question- 
answer frame was broken and students needed to do other sequential work to make connected discourse.

This research has highlighted the need for ethnometholdological studies to examine the particular work being accomplished by participants in co-constructing connected discourse rather than assuming a one to one form-function mapping for a more discrete concept like topic. In analyzing connected discourse, we are describing practices for coherence that every speaker must engage in when producing a series of turns at talk with other interlocutors. These connected turns may turn out to be thematically related and continue as an easily identifiable 'topic' but often, though related and coherent, we cannot easily say that a series of turns is part of one topic and another series is part of a next topic.

Researchers interested in language assessment have also looked to getting 'topic' underway as a way to better understand what actions and practices are developed by learners with advanced proficiency. Gan et al (2008), investigating how students maintain coherence during their oral assessment interaction, found that in topic sharing and turn allocation, there was a strong orientation to the task (oral language assessment). The participants used metatalk to show their awareness of and orientation to the task as one of assessing one another's language. The authors also found that the interactions featured disjunctive topic shifts (Sacks, 1992) which they saw as evidence of a developing repertoire of practices for producing connected, topical talk.

Huth \& Betz (2019) found that students who are engaged in conversational interactions designed to assess their spoken language consistently used the question-answer participation frame (Mori, 2002) when getting their talk underway. Although there were differences among the learner pairs in the degree to which movement through topics was disjunctive, one common practice for doing topic introduction was to ask their interlocutor a question.

\subsection{Change over time}

To understand how learners' practices for connected discourse change over time, researchers have engaged in studies using longitudinal data collection methods in out of classroom settings. Kim (2017) investigated the starting practices of two teenaged learners of English over the course of their nine months of work with an in-home tutor. The research shows how at the start of the recorded interactions, the learners did not initiate conversations but over time, this increased, starting with abrupt initiations. In the final stage of the data collection, the learner used the accumulated shared knowledge developed with his interlocutors to get conversations started by inquiring about some aspect of the tutor's life.

In research on German speaking au pairs using French as an additional language, König $(2013,2020)$ has also shown how learners use and orient to abrupt topic introductions. Evidence of development is seen when the learners repair the abrupt introductions. She also shows that, in general, over a nine month period, there is a trajectory for learners developing more elaborate and contextualized topic changes that show an orientation to place, time, and to the interlocutor. König (2020) also highlights how closely aspects of language learning are tied to the context in which the language is being learned and used. In accounting for the change she saw in her research participants, König reminds the reader of how after nine months of living with a new family, the au pair has knowledge of many and intimate details of the family. The au pair interacts with more of an identity disposition of family member than employee. Such a shift in identity plays a role in the types of and methods for getting conversational topics started. 
Sert's 2019 investigation of what he calls 'active listenership' draws on large database of small group peer interactions of ESL students doing discussion tasks. These tasks are not directed by a teacher so are, like the context in König's data, similar to mundane conversation. This case study traced the trajectory of change of one group of three undergraduate ESL students over the course of one year and found the group diversified their repertoire for interactional practices for responsive actions. These included more fluently timed responses, collaborative completions (Lerner, 1991), and proffering candidate lexical items which all act to achieve topical coherence. These findings highlight the collaborative nature of talk and the author raises important questions about assessing competence of individuals when what interaction entails the language use of more than one participant.

Past research shows us the importance of investigating topic as a co-constructed, contextualized process. The research shows that the degree to which interlocutors know one another, where they are interacting and for what purpose, influences how and why conversational topics get started. Research also shows evidence for a trajectory of learning to start conversations from a reliance on asking questions and introducing topics abruptly to producing introductions that are more contextualized and recipient-focused.

In the setting for our investigation, the activity type is especially relevant for seeing how learners develop ways to get conversations started. The three participants we focus on (Korean university students in Korea) were paid to get together weekly to speak English for an hour. The participants were asked to make a monologic presentation after which they were told to 'have a conversation' for 15 minutes. In such a setting, getting a conversation going presents a particular set of challenges. We see two sets of frameworks for order involved, similar to what Goffman termed 'system constraints' and 'ritual constraints' (1981). The participants' goals for their meetings was to increase their language proficiency by having time to practice using the language regularly. Achieving expert speaker status means the ability to handle the language system in a natural, that is, situated way. Added constraints are the academic or institutional aspect of the scheduled weekly time, the payment for participation, and the preset format for the meetings. However, all participants in interaction, regardless of the setting, must accomplish accountable language practices working with fellow humans who, in this case, share a particular goal.

What we see, generally, is a gradual addition of different actions that show a changing orientation to the activity type they are engaged in. The increasing repertoire of actions (Hall, 2018; Hellermann, 2018) coincide with the shift to a more flexible, interpersonal turn taking and turn allocation, showing the inseparability of sequence and action (Levinson, 2012). Rather than focusing on individuals or utterances alone, we want to assume that, although there is a goal to increase their language proficiency, because the same participants are interacting over time, there is a change in proficiency as a group (Hellermann, 2011; Konzett-Firth, 2019). The participants are enacting and developing relationships (Enfield, 2013) as fellow students and group mates and language learners and to do that they engage in, first and foremost, cooperative action (Goodwin, 2017) with the result being the development of practices for such cooperative action.

\subsection{Methods}

As part of a larger university initiative, undergraduate students at Sogang University who were not enrolled in English language classes were solicited (and paid) to participate in a 
conversation group program for purposes of practicing their English ${ }^{3}$. Eight groups of three students were enrolled in the study, agreed to be video recorded, and met weekly in the same groups. The format for these meetings was for each of the three participants to speak for 10 minutes uninterrupted (monologue). When each participant had had their ten minutes of uninterrupted talk, the group then was to have a 10-15 minute conversation. For this paper, we have transcribed and analyzed one of the groups and focus on the practices for connected discourse during the conversational time at three points in time during over the course of 94 weeks. Transcriptions were made following conventions for multimodal conversation analysis inspired by Mondada (2018). The practices for comparable actions were analyzed at different points in time to trace evidence of change (Hellermann, 2008; Markee, 2008). The first period (t1) is weeks 1-4 from autumn 2016, the second (t2) is weeks 54-58 (from autumn/winter 2017/18), and the third ( $\mathrm{t} 3$ ) is weeks 90-94, autumn 2018. The total time of interaction analyzed is 201 minutes over the course of two years.

We present 10 excerpts from the group of speakers who called themselves 'EEnglish' to illustrate changes in the participants' methods for topic development and orientation to participation framework as part of the work to make connected discourse. The participants are referred to as C, S, and $\mathrm{G}$.

\subsection{Data Analysis}

\subsection{Sessions 1 and 2: Orientation to question-answer/telling}

As stated above, the conversational portions of the early sessions were characterized by questions by members of the group to the just-finished presenter followed by the presenter's response which took the form of short tellings. In such cases, topics do not arise out of either the question or the response actions. Excerpt 1 comes from the group's first meeting at the point when the third participant, $C$, is finishing his monologue/presentation. He had been talking for ten minutes about a running club of which he is a member. As instructed, when the time runs out, the current speaker can end the monologue. And when that person is the third speaker, the dialogic part of the meeting can start. In excerpt 1 , the participants maintain this presenter-audience participation framework (Goffman, 1981) when $G$ and $S$ ask questions of the most recent presenter, $\mathrm{C}$.

\section{(1)}

[EEng1ish01 oct. 242016 605-664 33:35-35:51]

( $C$ was speaking about a running club he is a member of))

$11 \mathrm{C}$ : this is the end of (.) my: $(0.5)$ speech.

12 (1.0)

$13 \mathrm{C}$ : thank $\mathrm{y}(\mathrm{h}) \mathrm{ou}$.

$14 \mathrm{G}$ : ((taps on table 13 times))

$15 \mathrm{G}: \quad$ oka: : : yi

$16 \mathrm{~S}:$

17

(2.0)

$18 \mathrm{G}$ : >yeah< so, (0.5) how: : (1.5) much did you spent that

19 day $\dot{c}$

20 (1.5)

$21 \mathrm{C}$ : oh ((coughs)) I didn't count (.) that but ah- it was

22 (.) uh- (0.5) only a little=about twenty thousand won?

$23 \quad(1.5)$

\footnotetext{
${ }^{3}$ This work was supported by Global Research Network program through the Ministry of Education of the Republic of Korea and the National Research Foundation of Korea (NRF-2016S1A2A2911491).
} 


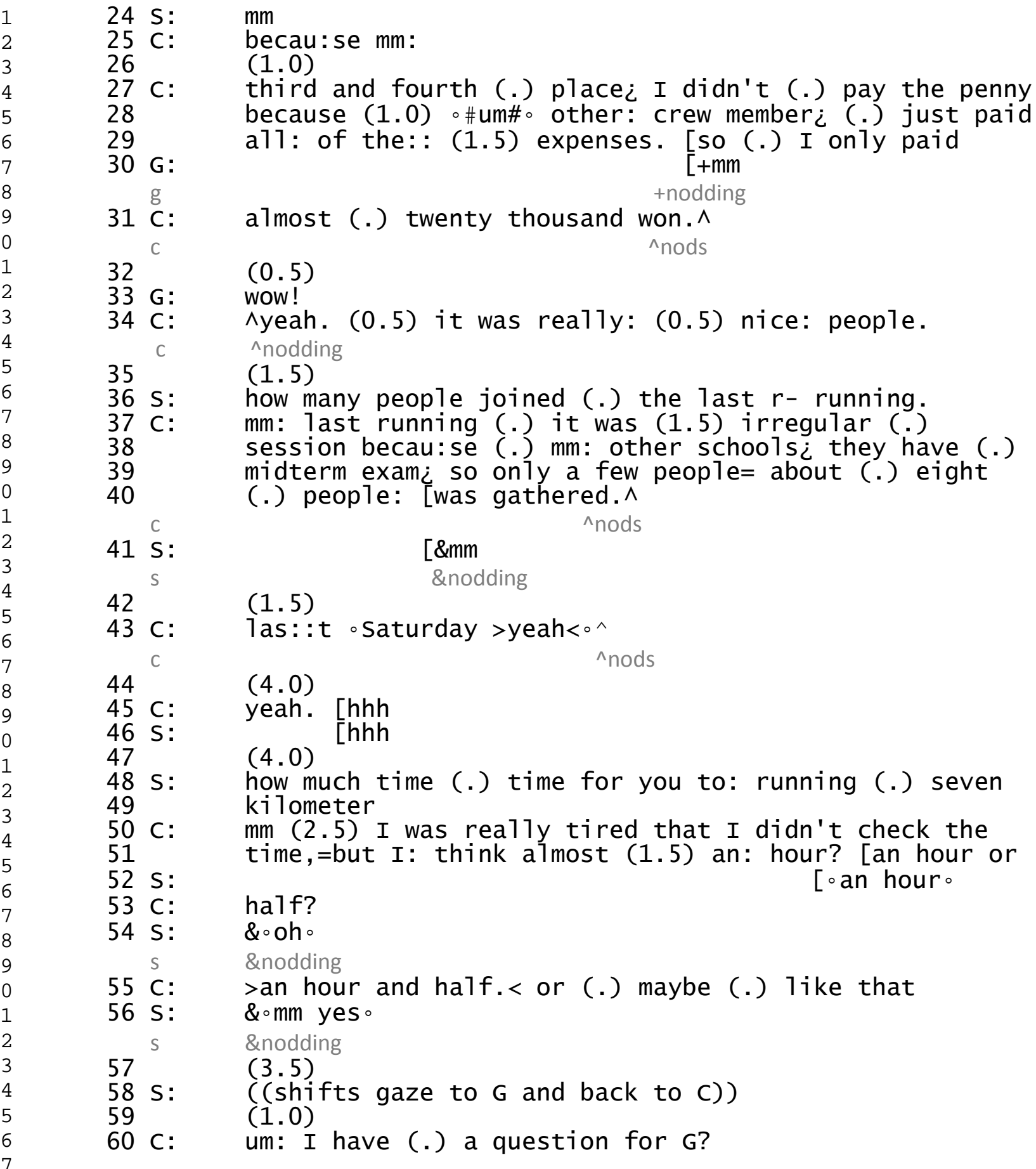

After $\mathrm{C}$ finishes his monologue with the explicit announcement in line 11, after a little transition time, $\mathrm{G}$ starts the conversational portion of the meeting with a question to C (II. 1819) about his spending during the day he discussed. C answers (starting in II. 21-22) with an assessment and estimate. This is followed by minimal receipt and several points where it would be relevant for a next speaker to comment on or ask follow up questions about C's answer (II. $30,32,35)$. Without other co-participants taking a turn, C continues with an account (II. 25-31). The assessment by $\mathrm{G}$ in line 33 is met with a second aligning assessment by $\mathrm{C}$ which is also hearable as a possible preclosing to C's answer and account. After a 1.5 second pause, S orients to C's turn as topic closing and asks his first question (I. 36) about the number of participants. C 
responds, which receives minimal receipt in I. 41 (followed by long inter-turn gaps: II. 43, 44, 47) and no development of the topic during that time, and S asks a second question about C's event, about the time it took him to run (I. 48). After C's response, there is no further development, minimal receipt from $\mathrm{S}$ and a pause. $\mathrm{S}$ shifts his gaze to $\mathrm{G}$ and in line $60, \mathrm{C}$ marks his next turn as a role switch, with a pre-question announcement to $G$.

It is notable in (1) that in lines 21 or 37 , in response to the questions from $G$ and S, C does not produce a short answer such as:

\section{G: 'how much did you spend?' \\ C: '20,000 won'}

or

$$
\begin{aligned}
& \text { S: 'how many people were there?' } \\
& \text { C: 'eight' }
\end{aligned}
$$

Rather, $\mathrm{C}$ is orienting to the topic-relevant nature of the inquiry treating the second position response as a place to provide detail about his monologue. However, other than minimal receipt, questioners $\mathrm{G}$ and $\mathrm{S}$ do not pursue the original inquiry as a topic. They do not ask follow up questions about or assess C's tellings (Maynard, 1980; Mori, 2002) nor do they add related information to develop these responses as conversational topics.

In meeting 2, there is a similar orientation to the question-answer structure in getting the conversation started with turns that do little topic development. After $\mathrm{C}$ explicitly ends his monologue about his weekend activities with an assessment and stopping the timer (I. 830), G starts the conversational portion by asking two questions (II. 842-843 and I. 860) of the justfinished presenter (C) after which S also asks a question of C (I. 866).

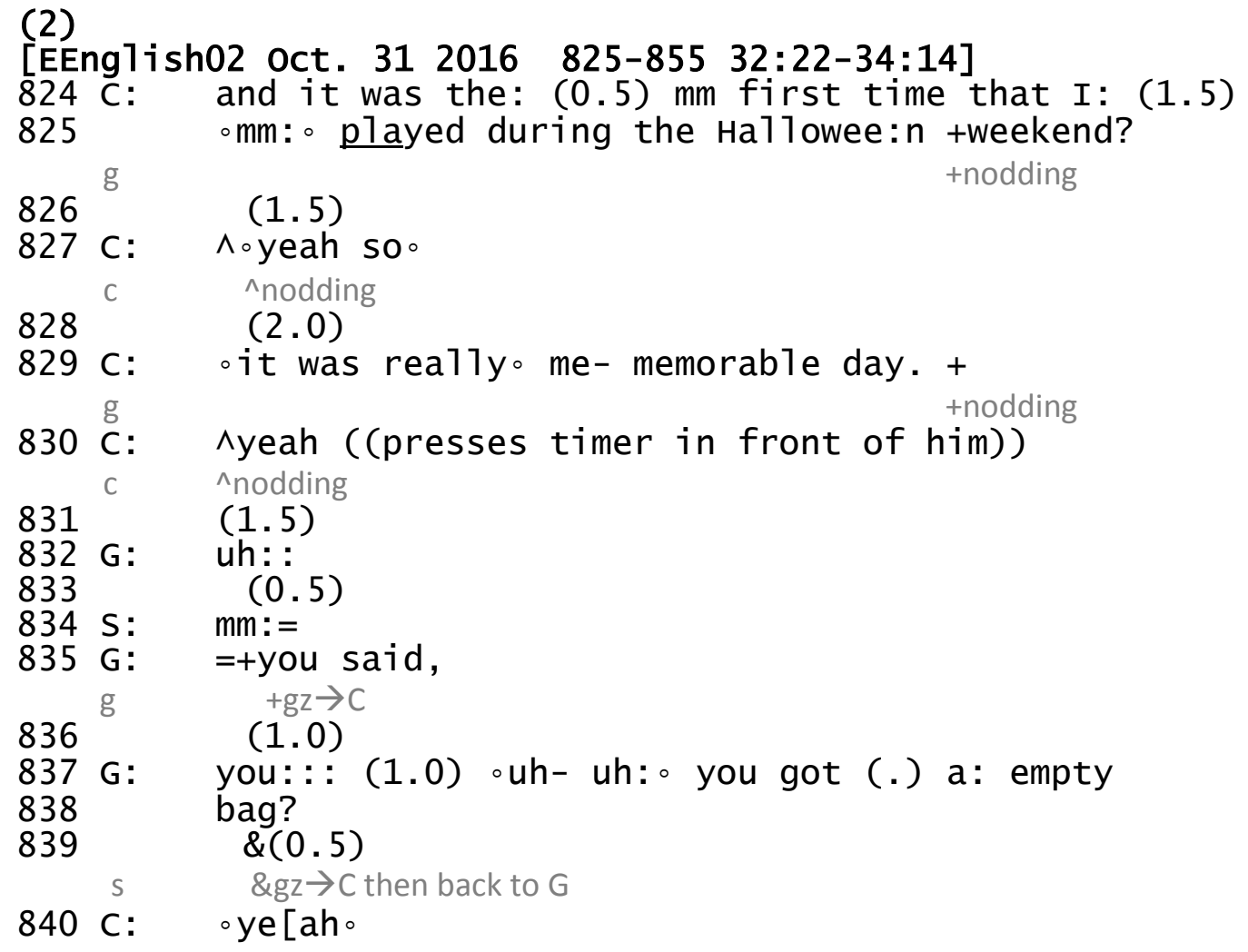


843 [uh three: olive people。

$\& g z \rightarrow C$

$844 \mathrm{C}: \quad[\circ() \circ$

$845 \quad(1.0)$

846 C: but (.) uh: (.) I think the: (.) th- they said

847 (0.5) the reward $i$ sh- was different? but (1.0)

848

849

850

$<$ I think that> (1.0) all the reward was the

same. (1.0) >because< in the bag there was

just $u: m(2.5)$ pape: $r$, which (1.0) osays that

851

852

$853 \mathrm{G}$ :

the:॰ (1.0) promotion o:f (2.0) ०uh: spa?。 (.)

$854 \mathrm{C}: \quad$ s $\quad$ yeah yeah $1 \mathrm{k}$ ke that<

855 c: but ${ }^{\text {c }}$ h I think it was a11 the same. we, we:

856 didn't (1.0) have a11 ^three: 1ives:

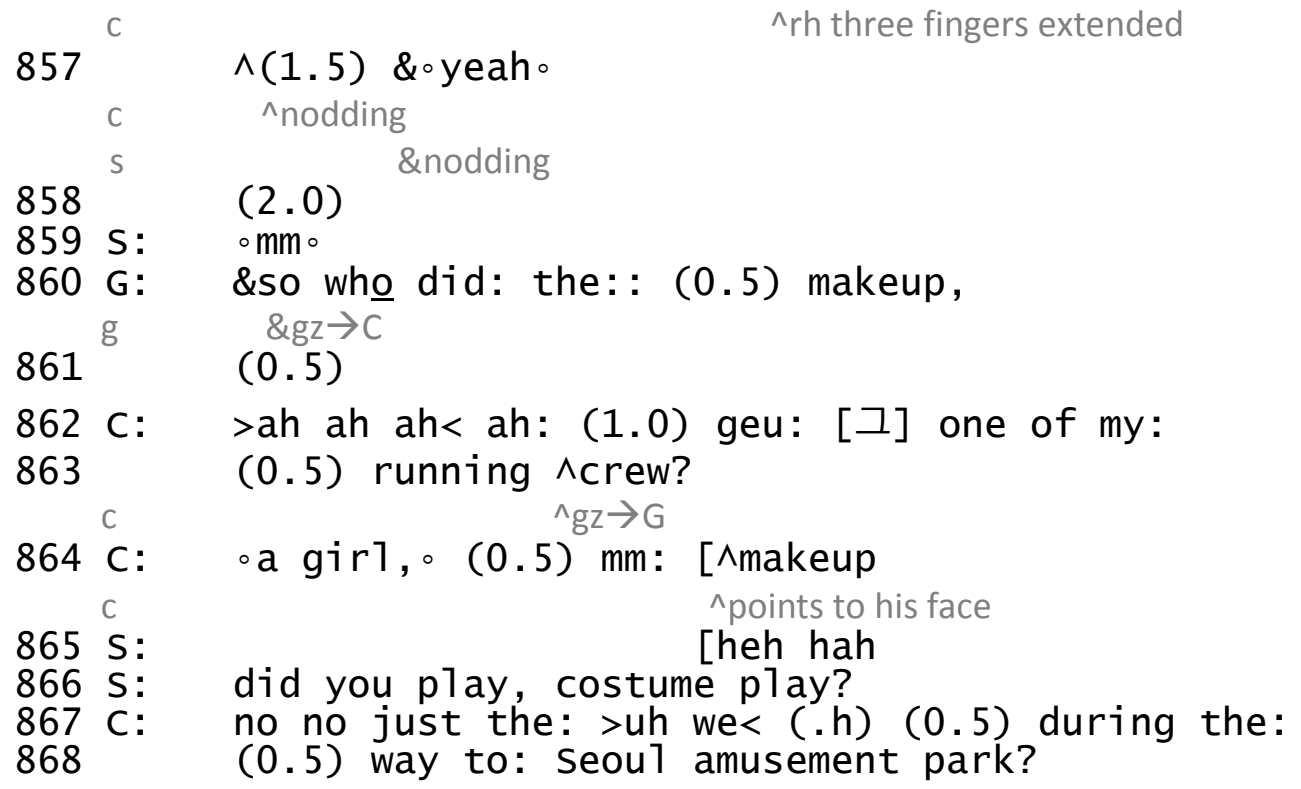

C ends his monologue about how he spent the past weekend (II. 825-834). In his monologue, C had told the group about participating in a Halloween event in which they received prizes for evading zombies and maintaining their lives (the 'lives' indicated by strings that they received from the promoter of the game). The final assessment of his weekend activities (I. 829) is followed by no more topic expansion and minimal receipt by co-participants. $G$ then shifts his gaze to $C$ and asks the first of two questions, this first one with a lengthy preface similar to news interview (Clayman \& Heritage, 2002) before getting to the question in II. 842-843 (what is the reward for three live people). After C's answer, G asks a second question (I. 860) which is relevant to the overall topic of C's Halloween experience (makeup) but does not develop the specific topic of the first question - the reward for the game that $\mathrm{C}$ and friends were participating in. C answers G's second question (II. 862-864) after which S proffers his first question (I. 866), also categorically related to the overall topic (asking about cos play) but not 
developing the previously mentioned items of the game, the person who did the makeup, or the process of doing the makeup.

Then, as in the first recording session, $\mathrm{S}$ asks a second question to $\mathrm{C}$ and after some explanation by $C$, the roles change and $C$ asks a question of another group member (excerpt (3), II. 926-927), explicitly allocating the turn to $G$ through his gaze and pointing gesture.

(3)

[EEnglish02 oct. 31 2016 922-929 35:14-35:43]

$922 \mathrm{G}:=\mathrm{e}-$ even thou:gh there are: there were so:

923 many (.) people in Itaewon or Hongdae or:

$924 \quad(1.5)$ near: (1.0) developed uh: (1.0) place.

$925 \quad(3.5)$

$926 \mathrm{C}$ : what $\wedge$ what did you do during the:

927 C: weekend\&?

$\wedge \mathrm{gz} \rightarrow \mathrm{G}$, points $\rightarrow \mathrm{G}$

\& $\& g z \rightarrow G$

$928 \mathrm{G}:$ ah: I just $(0.5)$ uh:: : (1.0) hang around with

929 a friend? who: : is working?

The interactions from the openings of sessions 1 and 2 show a clear orientation to the participation structure of an interview (Huth \& Betz, 2019) with a series of questions about the speaker's monologue and responses that are somewhat extended, similar to a telling. Unlike other research on unacquainted groups (Maynard \& Zimmerman (1984); Svennivig (1999), the participants do not proffer questions about their co-participants' personal lives as topical and ticket into a conversation.

Session 3: Topic development via stance and shifting participation framework

In the group's third meeting, two weeks after the first, there is evidence of a change in the actions the group uses to move out of the monologic sequence of presentations and into a discussion oriented to the topics of each monologue. Rather than the question/answer participation framework from the first two sessions, in session 3 we will see that a topic is developed through a variety of actions related to the expression of stance. This begins with an assessment solicitation $(G)$, a challenge to the implication of that solicitation $(C)$, a response to that challenge $(\mathrm{G})$, a suggestion $(\mathrm{C})$, and an assessment by the third participant (S).

In (4), the last presenter in the group, (G) ends his monologue about the many achievements of Korean sportspersons with the similar explicit ending marking seen in sessions 1 and 2 (1. 49: this is the end of my story). G then solicits assessments from his two interlocutors (II. 53-59). This already breaks the participation framework from sessions 1 and 2 as $G$ is the last presenter and the person who initiates the conversation. $C$ responds with a qualified response that aligns with G's implication (II. 62-71) but his turn continues with a kind of challenge to $G$ ((II. 77-78), asking $\mathrm{G}$ to account for the implication in his question (that one should be proud of being a Korean because of Koreans' achievements in sport). When $\mathrm{G}$ does not respond (I. 79) C proffers a more specific question: what do they give us (II. 80-82).

(4)

[EEnglish03 Nov. 7 2016 1446-1480 31:10-32:12]

$45 \mathrm{G}$ : good place to live.

$46 \quad(0.5)$

$47 \mathrm{G}:$ so: 
$48 \quad(0.5)$

$49 \mathrm{G}$ : $\quad$ this is end of my: story^. okay $>$ (and)< 
[EEnglish03 Nov. 72016 1527-1557 33:04-34:06]

27 C: maybe:

$28 \quad(1.0)$

$29 \mathrm{C}: \quad \cdot \mathrm{h}$

$30 \quad(1.5)$

$31 \mathrm{c}$ : you see: $\wedge$ here,\&

$32^{\mathrm{g}}(1.5) \quad \& g z \rightarrow \mathrm{S}$

$33 \mathrm{C}: \quad$ jorda[n?

34 G: $\quad$ [michael jordan.

$35 \mathrm{C}: \quad>1 i k e$ like< hi(h)m .h we ^should make

$36 \quad(0.5)$

$37 \mathrm{C}$ : $\quad$ some $\wedge$ friend. of $\wedge$ our, $\wedge$ rh palm up gesture toward G

$38 \mathrm{G}: \quad=$ yes.

39 C: best [players

40 S: $\quad$ : $\quad$ \&mm

$s \quad$ \&nodding

$41 \mathrm{C}$ : $\quad$ and sel1 it (.) abroad and

$42 \wedge(1.0)$

C $\quad \wedge$ nodding and $g z \rightarrow S$

43 C: +yeah.

44 S: $\quad$ e sports is also:

$45 \quad(1.0)$

$46 \mathrm{~S}: \quad>$ is sports.< (Clines missing: S reminds peers about olympics being in Korea))

$65 \mathrm{~s}: \quad i t$ 's hard to explai:n what is the benefit of:

66 the sports.

The group discusses this topic until it winds down (excerpt (6), II. 40-50) and G asks C (addressing him by name) a question about the topic of his monologue. The question does not occur until lines $80-84$ because there is a lengthy preface to the question. Note that G's question is also embedded in an assessment: $\mathrm{G}$ indicates he also wants to live independently (in a studio apartment) and then implies that $C$ is not truly independent of his parents.

(6)

[EEnglish03 Nov. 72016 1638-1697 35:16-36:19]

$38 \mathrm{~S}: \quad \mathrm{NC}::$ :

$39 \mathrm{G}: \quad=$ soft?

$40 \mathrm{~S}: \quad=>\mathrm{NC}$ soft? $<$

41 (1.5)

42 S: $\quad j->$ uh< NC soft buy:, ah sponsored (.) the

43 basebal1 team.

$44 \quad(1.0)$

$45 \mathrm{G}: \quad+$ yes

46 g t +nodding

46 C: $=\mathrm{mm}:$

$47 \mathrm{~S}: \quad=$ because they: >are< earned

48 (0.5)

49 S: \&som- (.) much money.

$S \quad$ \&nodding 


\begin{tabular}{|c|c|c|}
\hline 50 & & $(0.8)$ \\
\hline 51 & G: & +okay so C, (.) uh: : \\
\hline 52 & $\mathrm{~g}$ & $\begin{array}{l}\text { +nodding } \\
(1.5)\end{array}$ \\
\hline $\begin{array}{l}53 \\
54\end{array}$ & G: & $\begin{array}{l}\text { I also want to: : (2.0) li:ve in the studio } \\
\text { apartment, } \\
\text { ((1ines missing - more prefacing work to the question)) }\end{array}$ \\
\hline $\begin{array}{l}80 \\
81\end{array}$ & G: & $\begin{array}{l}\text { so: do you thi:nk (.) uh: are you:: } \\
(3.0)\end{array}$ \\
\hline $\begin{array}{l}82 \\
83\end{array}$ & G: & $\begin{array}{l}\text { uh: : } \\
(1.0)\end{array}$ \\
\hline $\begin{array}{l}84 \\
85\end{array}$ & G: & $\begin{array}{l}\text { perfectly: (.) dep- independent } \\
(0.5)\end{array}$ \\
\hline 86 & S: & $\& m m$ \\
\hline & $\mathrm{s}$ & \&nodding, gz $\rightarrow C$ \\
\hline $\begin{array}{l}87 \\
88\end{array}$ & G: & $\begin{array}{l}=\text { to your parents, } \\
(0.5)\end{array}$ \\
\hline $\begin{array}{l}89 \\
90 \\
91\end{array}$ & G: & $\begin{array}{l}\text { just: living in the: (2.0) studio apartment? (.) } \\
\text { do you feel like (.) independent? } \\
\text { (0.5) }\end{array}$ \\
\hline $\begin{array}{l}92 \\
93\end{array}$ & S: & $\begin{array}{l}\text { \$no hheh hah\$ } \\
=\$ \text { no because I \$ }\end{array}$ \\
\hline
\end{tabular}

In their third session, the group moves beyond the interview participation framework when the questioner $(\mathrm{G})$ embeds his opening question in an expression of his stance toward the just-finished monologue about how sports may make a Korean person proud of being Korean. He then solicits opinions of his peers. We see a continued orientation to the question-answer structure of sessions 1 and 2 as G proffers a second question to C (I. 51) but that too is more provocative of topical talk in that it is designed to have the recipient align or disalign with the questioner's own stance toward the topic: living situations in this case.

\subsection{Session 4: More cooperative work in the interaction}

The first three sessions were notable for the participants enacting roles of questioner and responder. Session 4, from eleven days after session 3, is more cooperative in the way assessments and overlap at transition relevance places are carried out. For the sake of space, we will only show the details of one assessment and the overlapping talk.

The start of the conversational part of the meeting was as we have seen: $\mathrm{G}$ had asked the last presenter, $\mathrm{C}$, a question about a placement examination that he took during the past year. C's response was an emotionally-laden telling. C's telling has an assessment in II. 10-11 when $\mathrm{S}$ (the third party) offers his own assessment of the solution to an excess of exam takers (II. 12-16). This is notable, again, because $\mathrm{G}$ asked a question to $\mathrm{C}$ who answered it. Rather than asking a question or waiting for $\mathrm{G}$ to ask another, $\mathrm{S}$ orients to the assessment made by $\mathrm{C}$ and contributes to developing a topic by offering his own unsolicited opinion on the matter.

\section{(7)}

[EEnglish04 Nov. 182016002002 0:00-9:00]

( ( $G$ asks a question to $C$ about what it was like to prepare for and take a particular high stakes exam ('suneung') and C answers G's question))

$10 \mathrm{C}$ : retaker. so (.) it's kind of uhm (.5) not good cycle but (.)

11 it could be compensated as trying one more year.

$12 \mathrm{~s}$ : I think that: people who retry the exam (.) is-there are 


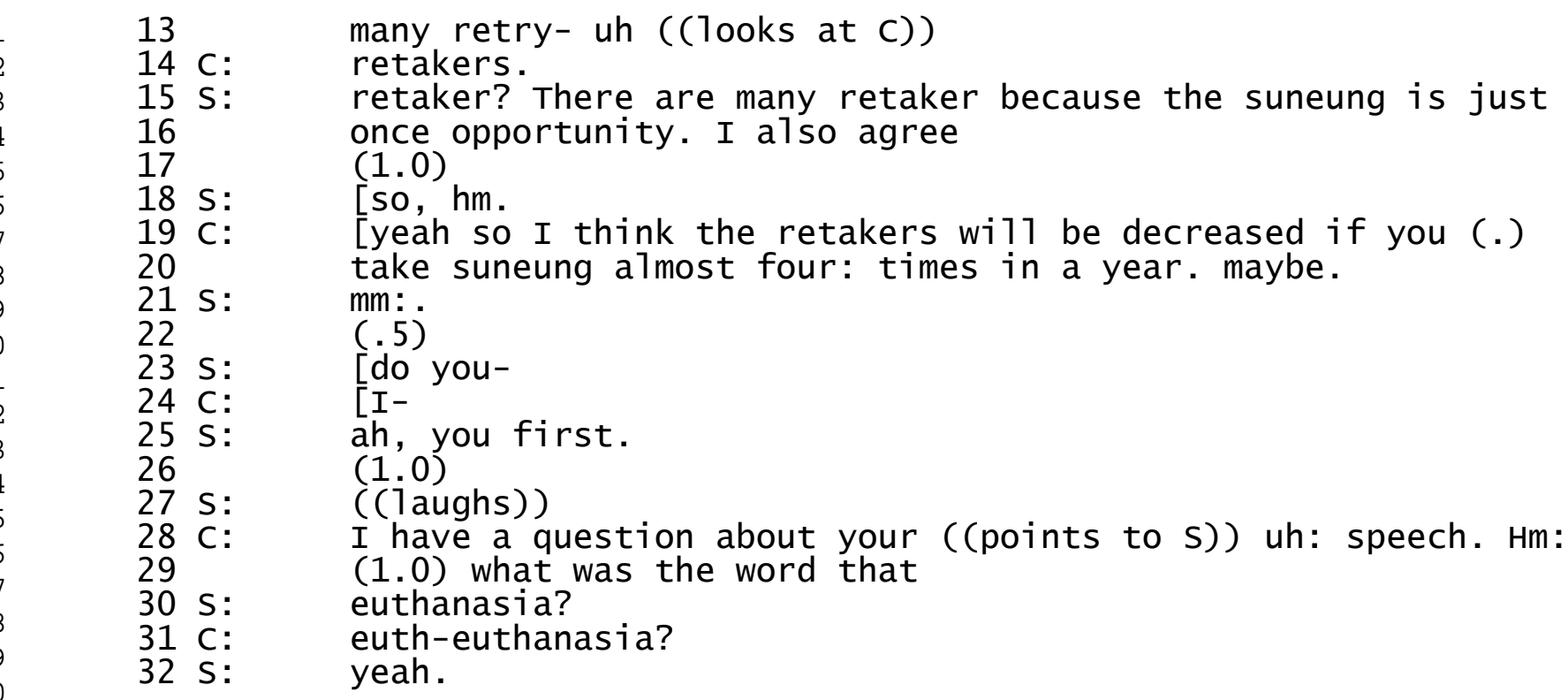

After a short gap (I. 17), we see some overlap at the start of a next turn. Although S's assessment just prior (line 16) projects that speaker change is relevant, the one-second gap is oriented to by $\mathrm{S}$ and he self-selects to continue speaking at the same time as $\mathrm{C}$ who makes a closing kind of summary to his assessment of the test taking situation. After a minimal agreement token by S (I. 21) and a .5 second gap (I. 22), there is overlap again by $S$ and $C$ at this transition relevance place after which $S$ does some explicit turn allocation work (I. 25), offering the next turn to $\mathrm{C}$.

As with the excerpts from sessions 1-3, the conversational part of the meeting gets underway via questions proffered by a group member to the most recent presenter (G questioning $\mathrm{C}$ ). What is different here, however, is the more collaborative participation seen when the third group member $(\mathrm{S})$ gives his own answer to the question proffered to his peer, $\mathrm{C}$. This response (as well as his aborted turn continuing his talk in line 23) shows an orientation by the group to a more open turn-taking procedure than we saw in sessions 1-3.

\subsection{One year later: Evidence of closer collaboration and topic pursuit with explicit marking}

The following excerpts (from session 54, January 2, 2018) come from a little over a year after the last excerpts. Notable here are the actions that exhibit a closer collaboration in the construction of a dialogue. There is still some orientation to a question-initiated interview participation structure, but the action used to start that sequence is recycled, used by a second participant to maintain and develop the topic that was started. We also see collaborative completions and explicit marking of topic introduction.

$S$ is the last presenter and ends, in line 28 with an explicit marker it's end of how to quit smoking (the topic of his presentation). He then wishes his peers good luck for the new year (as it is January $\left.2^{\text {nd }}\right)$. After those wishes, $\mathrm{G}$ starts the conversational portion of the meeting with a prefaced question (II. 50-52), a personal question about S' plans for the new year. During a turn in which S displays some disfluency (I. 63), G provides a predicate (I. 65) to complete the unit that $\mathrm{S}$ had started. After $\mathrm{S}$ finishes his response, he then solicits the same information from the third participant, $C(I .70)$ thus developing a topic started with $\mathrm{G}^{\prime}$ s first question to $\mathrm{S}$. 
(8)

[EEnglish54 Jan. 2, 2018 ]

$28 \mathrm{~S}$ : $\mathrm{mm}$ okay it's: end of .h uh how to quit +smoking?

c $\quad$ +nodding (lines missing - S gives an epilogue to his presentation

about new year's resolutions))

$50 \mathrm{G}$ : $\quad$ so: you first ask u:s what's the: new year's plan

$51 \stackrel{\mathrm{g}}{(\mathrm{C})} \quad \hat{\mathrm{gz} \rightarrow \mathrm{s}}$

$52 \mathrm{G}: \quad$ the: $\quad$ what's your: (.) new year's, plan? (.)

$53 \mathrm{~S}: \quad$ I have $(0.5)$ two plans for .h this years?

54 [.h uh: (0.5) first, (.) uh first thing i:s

55 G: $\quad$ oh okay,

$56 \mathrm{~S}: \quad$ uh $(2.0)$ exercise? $[\mathrm{mm}:$ um (.) make a (1.0) health (.)

$58 \mathrm{~S}$ : healthy body? and second thing is (.h) uh

59 (1.0)

$60 \mathrm{~S}: \quad$ studying English more (.) more than (.) last year,

61 (): $\mathrm{mm}$ :

62 (1.0)

$63 \mathrm{~s}: \quad$ especially focusing $i: n$ (1.0) um

$64 \quad(1.0)$

$65 \mathrm{G}: \quad$ speaking, $=$

$66 \mathrm{~S}: \quad=$ speaking.

$67 \mathrm{C:} \quad \mathrm{hm}$

$68 \mathrm{~S}$ : $\quad$ not reading o:r (1.0) listening. ah- not reading,

69 (2.5)

$70 \mathrm{~s}: \quad$ how about $\mathrm{C}$ ?

$71 \quad(1.0)$

72 C: um (4.0) I'm (.) planning to (2.5) mm: (0.5) maybe

In excerpt (9), which follows immediately from (8), G makes another collaborative completion (I. 80) during C's response to S's question. This candidate completion shows how highly attuned $\mathrm{G}$ is to the production of $C^{\prime}$ 's turn as the production of 'the' in line 79 with a high front vowel [i] (shown in the transcript with the spelling <thee>) projects a next noun phrase starting with a vowel which $\mathrm{G}$ produces (important).

(9)

[EEnglish54 Jan. 2, 2018 ]

$70 \mathrm{~S}$ : how about $\mathrm{C}$ ?

71 (1.0)

$72 \mathrm{c}$ : um (4.0) I'm (.) planning to (2.5) mm: (0.5) maybe

73 getting a job,

74 (0.5)

$75 \mathrm{~s}: \quad \mathrm{mhm}$

76 C: $\quad$ this year, (1.0) it's big plan,

77 (0.5)

$78 \mathrm{~s}: \quad$ yeah=

$79 \mathrm{C}: \quad=$ and thee:

$80 \mathrm{G}$ : important plan,

$81 \mathrm{C}: \quad$ ultima(h) te $(0.5)$ destination?=maybe,

$82 \mathrm{~s}: \mathrm{mm}$ :

83 (1.5) 
In the last excerpt, (10), from November of 2018, more than two years after the first session, we see evidence of a further shift to more collaborative, less scripted format for the conversational part of the interaction in the precision timing, turn taking actions, and meta talk about topic.

At the start of excerpt (10), $\mathrm{C}$ is finishing his monologue and we see that the explicit reference to closing the monologue continues through the two years of meeting (I. 8). We also see that the group still may start the conversational portion with a question (II. 12-20) as G begins with a clarification question about whether molecular gastronomy includes the preparation of insects. $G$ starts this part of the interaction, however, without delay (as a contrast, see excerpts 1, 2, and 4). Before $C$ can respond to $G^{\prime}$ 's question, $S$ interjects with an assessment of $G^{\prime}$ 's question - that it may not be relevant to C's topic (I. 21). After some repair work about the terminology, $\mathrm{S}$ then shares his own experience with experimental food preparation (starting in line 30, lines are omitted for the sake of space). Note that $\mathrm{S}$ ties his contribution to C's monologue with the preface of the terminology C used (I. 24) that he, S, is not familiar with it. $C$ asks a clarifying question about where $S$ has experienced all of this experimental food he has talked about and $\mathrm{C}$ assesses that information as 'very surprising' (I. 49). Immediately after this, G (II. 51-53) introduces a related topic (the convenience of getting nutrition in pill form) with the explicit orienting to topic coherence with the comment about its relevance. This leads to a question that is directed to $C$ (II. 63-64). Again, before $C$ can answer, $S$ orients to this activity type as conversational talk rather than interview and asks a clarifying question (I. 65) about G's question.

[EEnglish90 001 Nov. 20, 2018 31:35-35:10]

$08 \mathrm{C}$ : this is the end of my speech;

$09 \mathrm{~s}: \mathrm{mm}$

$10 \mathrm{C}$ : ((turns over sand timer))

$11 \mathrm{~S}: \quad$ (clears throat))

$12 \mathrm{G}$ : does the geo-graphy geo-credit (.) [include

$13 \mathrm{C}$ :

$14 \mathrm{G}$ :

$15 \mathrm{C}:$

$16 \mathrm{~s}:$

$17 \mathrm{C}$ :

$18 \mathrm{G}$ :

19

[molecular

[molecular

[molecular

what? eh heh [heh

[gastronomy

molecular gastronomy: ((clears throat)) include

$\begin{aligned} \mathrm{g} & +\mathrm{gz} \rightarrow \mathrm{C}\end{aligned}$

tinsect alternative

food?

$21 \mathrm{~s}: \quad \mathrm{mm}$ I th[ink this little different?

22 C: [ah: yes

$23 \mathrm{G}$ : if that's +not merkuler, yeah

$\mathrm{g}:+\mathrm{gz} \rightarrow \mathrm{S}$

24 S: I don't know about uh merkular wh(h)at? Eh heh heh

25 C: molecular

$26 \mathrm{G}$ : molecular gastography

27 C: $\quad$ gast ronomy.>

$28 \mathrm{G}$ : gastronomy.

$29 \mathrm{~s}: \quad$ molecular gastronomy uh is first time to hear that termi

30 but, I already ate some of the (.) that food; like () ice

31 cream

$32 \mathrm{G}$ : $\mathrm{mm}$ 
((1ines missing: S talking about experimental food preparation))

$47 \mathrm{C}$ : you: did it in your school?

48 S: yeah;

49 C: $\quad$ very surprising

$50 \mathrm{~S}: \quad$ yes science class.

$51 \mathrm{G}$ : I don't think I can- I'm not sure if this topic is related to

52 gasotropy but I really like to develop or have one pills that

53 have most nutrition for one meali

((1ines missing $\mathrm{G}$ prefaces his question))

$63 \mathrm{G}:$ tif there exists a pi11, do you prefer to use that (.) pi11s

$64^{\mathrm{g}} \quad$ or just eat out. $=$

$65 \mathrm{~s}: \quad=i \mathrm{t}$ tastes good?

66 G: same.

Like the previous examples, in (10), there is an explicit marking of the end of the monologue and some orientation to the interview structure with $\mathrm{G}$ starting off the dialogic portion with a clarification question to the last speaker. However, here the interview structure breaks down as the third party, S, comments on the question that was not addressed to him. G responds to that comment and then $\mathrm{S}$ tells about his experience with the new gastronomy. $\mathrm{C}$ asks a clarifying question about S's telling, continuing to develop the current topic, and offers an assessment. And although $\mathrm{G}$ continues to orient to the interview structure with a second question to the last teller, $C$, using a (typical for him) lengthy question preface, the insertion sequence which follows (II. 65-66) involves the third party, S. In general, this excerpt provides evidence of a shift in orientation in the participation framework from two years before. We see the shift in the different way that recipiency is co-constructed. Questions that appear directed to one party are assessed and answered by another party. We also see specific mentions of topic coherence before questions are proffered.

\subsection{Discussion and Conclusion}

An etic, quantitative analysis of the conversations of this group showed us that the rate of speech and the diversity of discourse markers used increased over the course of the two years (Relampagos, 2019). By these measures, the talk is more fluent. Such findings became a starting point for our analyses. We have looked for explanations for how such changes in the use of language come into the participants' repertoires by investigating the process of how a group of the same three participants develop methods for interaction that facilitate or catalyze such changes.

The findings from our sequential analysis shows us that there are turn taking and turn allocation procedures that remain consistent over the course of 90 meetings such as the explicit comment to close a monologue and the questions proffered to the just-finished presenter. Our findings also support earlier research that language learners who are asked to interact conversationally rely on an ordered turn taking in which novice speakers ask questions of their interlocutors (Mori, 2002; Huth \& Betz, 2019 - see similar findings for unacquainted interlocutors, Maynard \& Zimmerman, 1984). In our data, at the start of their 94 weeks of interactions, the group fulfilled the assignment to 'have a conversation' by proffering directives to the just-finished presenter, directives which sought information or clarification. This was done by one of the participants, not the last presenter, self selecting to proffer a question to the last presenter who then answered. Orienting to lack of comment on that response, the last presenter continued the response into a short telling. In subsequent meetings, different actions 
are accomplished and added to the group's repertoire: overlap and turn competition, assessment proffers and assessments of both the topic and the questions about the topic. And with the addition of these actions, the turn taking and turn allocation structure becomes less rigidly ordered. As Sert (2019) found, there is more collaborative turn construction in the later interactions and thus, we see evidence of change in practices as one of mutual adaptation (Konzett-Firth, 2019; Larsen-Freeman \& Cameron, 2008).

In our data, the participants were not given explicit instruction on how conversations work (cf. Huth \& Taleghani-Nikazm, 2006; Huth \& Betz, 2019) nor on how to start a conversation. The three participants are acquainted so the use of getting to know one another strategies (Maynard \& Zimmerman, 1984; Svennevig, 1999) are not relevant. Questioning about a co-participant's just finished presentation is treated as most relevant to starting a conversation. That questioning procedure did not, however, lead to productive topics. After engaging in this activity several times, however, new actions and interactional practices for accomplishing those actions appear ${ }^{4}$. These new actions and practices can be seen as evidence of increased listening comprehension (Sert, 2019) as well as a shift in the group member's identity dispositions (Pekarek Doehler \& Berger, 2018; König, 2020).

Individual identities may have played a role in the achievement of connected topic discourse. Our excerpts do not show $\mathrm{S}$ being the initiator of questions and overall, $\mathrm{G}$ and $\mathrm{C}$ appear more active. Our assumption is that in repeated interactions of this kind, local roles for interaction will solidify and then change over time. As part of the members' regularly meeting, they developed relationships to one another as group members (Enfield, 2013) who know and can share particular information and interact in a particular way. The displays and solicitations of stance in the later interactions show us a change in how the participants orient to one another as group members. They were seen learning the language practices of one another as individuals (the histories of each member and their knowledge) but to function as group members (who speaks how and when). This identity disposition and its development is seen in the structural elements of action formation (expression of stance, solicitation of assessment, assessment giving), turn construction (timing), and turn allocation (collaborative completions) showing the inseparability of action and structure (Levinson, 2012).

\section{References}

Arminen, I., \& Leinonen, M. (2006). Mobile phone call openings: Tailoring answers to personalized summonses. Discourse Studies, 8(3), 339-368.

Bardovi-Harlig, K. (1998). Narrative structure and lexical aspect: Conspiring factors in second language acquisition of tense-aspect morphology. Studies in Second Language Acquisition, 20, 471-508.

Button, G., \& Casey, N. (1984). Generating topic: the use of topic initial elicitors. In J. M. Atkinson \& J. Heritage (Eds), Structures of social interaction: Studies in Conversation Analysis (pp. 167-190). New York: Cambridge University Press.

\footnotetext{
${ }^{4}$ We saw little use of two strategies noted to be commonly used to introduce topics: the itemized news inquiry or news announcement strategies (Button \& Casey, 1985). In an excerpt we did not have space to show or analyze, in session 54 (15 months into the recording), C used the news announcement strategy to start the conversational portion of the meeting but two of the three uses were not picked up by his interlocutors.
} 
Clayman, S., \& Heritage, J. C. (2002). The news interview: Journalists and public figures on the air. Cambridge: Cambridge University Press.

Crow, B. (1983). Topic shifts in couples' conversations. In R. Craig \& K. Tracey (Eds.), Conversational coherence: Form, structure and strategy (pp. 136-156). Beverly Hills, CA: Sage.

Drew, P., \& Heritage, J. (1992). Analyzing talk at work: An introduction. In P. Drew \& J. Heritage (Eds.), Talk at work: Interaction in institutional settings (pp. 3-65). Cambridge: Cambridge University Press.

Enfield, N. J. (2013). Relationship thinking: Agency, enchrony, and human sociality. Oxford: Oxford University Press.

Gan, Z., Davidson, C., \& Hamp-Lyons, L. (2008). Topic negotiation in peer group oral assessment situations: A conversation-analytic approach. Applied Linguistics, 30(3), 315-334.

Goffman, E. (1981). Forms of talk. Philadelphia: University of Pennsylvania Press.

Goodwin, C. (1984). Notes on story structure and the organization of participation. In J. M. Atkinson \& J. Heritage (Eds.), Structures of social action: Studies in conversation analysis (pp. 225-246). Cambridge: Cambridge University Press.

Goodwin, C. (2017). Co-operative action. Cambridge: Cambridge University Press.

Givón, T. (1983). Universals of discourse structure and second language acquisition. In W. Rutherford (Ed.), Language universals and second language acquisition (pp. 109-127). Amsterdam: John Benjamins.

Hall, J. K. (2018). From L2 interactional competence to L2 interactional repertoires: Reconceptualising the objects of L2 learning. Classroom Discourse, 9(1), 25-39. https://doi.org/10.1080/19463014.2018.1433050

Hayashi, M. (2014). Activity, participation, and joint turn construction: A conversation analytic exploration of "grammar-in-action". In K. Kabata \& T. Ono (Eds.), Usage-based approaches to Japanese grammar: Toward the understanding of human language (pp. 223-258). Amsterdam: John Benjamins.

Hellermann, J. (2008). Social actions for classroom language learning. Clevedon, UK. Multilingual Matters.

Hellermann, J. (2011). Members' methods, members' competencies: Looking for evidence of language learning in longitudinal investigations of other-initiated repair. In J. K. Hall, J. Hellermann, \& S. Pekarek Doehler (Eds.), L2 Interactional Competence and Development (pp. 147-172). Bristol, UK: Multilingual Matters.

Hellermann, J. (2018). Languaging as competencing: Considering language learning as enactment. Classroom Discourse, 9(1), 40-56. https://doi.org/10.1080/19463014.2018.1433052

Holt, E. (2010). The last laugh: Shared laughter and topic termination. Journal of Pragmatics, 42, 1513-1525.

Huth, T. \& Betz, E. (2019). Testing interactional competence in language classrooms: Goals, formats, and caveats. In R. Salaberry \& S. Kunitz (Eds.), Teaching and testing $L 2$ interactional competence: Bridging theory and practice (pp.322-356). London: Routledge.

Huth, T., \& Taleghani-Nikazm, C. (2006). How can insights from conversation analysis be directly applied to teaching L2 pragmatics? Language Teaching Research, 10(1), 53-79. https://doi.org/10.1191/1362168806Ir184oa 
Jefferson, G. (1978). Sequential aspects of storytelling in conversation. In J. N. Schenkein (Ed.), Studies in the organization of conversational interaction (pp. 219-248). New York: Academic Press.

Jefferson, G. (1984). On stepwise transition from talk about a trouble to inappropriately nextpositioned matters. In J. M. Atkinson \& J. Heritage (Eds.), Structures of social action: Studies in conversation analysis (pp. 191-222). New York: Cambridge University Press. Jefferson, G. (2004). Glossary of transcript symbols with an introduction. In G. H. Lerner (Ed.), Conversation Analysis: Studies from the first generation (pp. 13-31). Amsterdam: John Benjamins.

Kim, Y. (2017). Topic initiation in conversation-for-learning: Developmental and pedagogical perspectives. English Teaching, 72(1), 73-103.

König, C. (2013). Topic management in French L2: A longitudinal conversation analytic study. EUROSLA Yearbook, 13, 226-250. doi 10.1075/eurosla.13.11kon.

König, C. (2020). A conversation analysis approach to French L2 learning: Introducing and closing topics in everyday interactions. London: Routledge.

Konzett-Firth, C. (2019). Co-adaptation processes in plenary teacher-student talk and the development of L2 interactional competence. Classroom Discourse, 1-20. https://doi.org/10.1080/19463014.2019.1597744

Lah, J., \& Lee, Y.-A. (2015). Role of discourse Markers in connected discourse: Sequential analysis of nonnative use. Korean Journal of Applied Linguistics, 15(2), 203-229.

Larsen-Freeman, D., \& Cameron, L. (2008). Complex systems and applied linguistics. Oxford: Oxford University Press.

Lee, Y. -A. (2006). Towards respecification of communicative competence: Condition of L2 instruction or its objective? Applied Linguistics, 27, 349-376.

Lee, Y. -A. (2012). Building connected discourse in non-native speech: Re-sepcifying non-native proficiency. Pragmatics, 22(4), 591-614.

Lee, Y.-A., \& Hellermann, J. (2014). Tracing developmental changes through conversation analysis: Cross-sectional and longitudinal analysis. TESOL Quarterly, 48(4). https://doi.org/10.1002/tesq.149

Levinson, S. C. (2012). Action formation and ascription. In J. Sidnell \& T. Stivers (Eds.), The Handbook of Conversation Analysis (pp. 101-130). Malden, MA: Wiley-Blackwell. https://doi.org/10.1002/9781118325001.ch6

Mandelbaum, J. (1993). Assigning responsibility in conversational storytelling: The interactional construction of reality. Text, 13, 247-266.

Markee, N. (2008). Toward a learning behavior tracking methodology for CA-for-SLA. Applied Linguistics, 29(3), 404-427. https://doi.org/10.1093/applin/amm052

Maynard, D. W. (1980). Placement of topic changes in conversation. Semiotica, 30(3/4), 263290.

Maynard, D. W., \& Zimmerman, D. H. (1984). Topical talk, ritual and the social organization of relationships. Social Psychology Quarterly, 47(4), 301-316.

Mehan, H. (1979). Learning lessons: Social organization in the classroom. Cambridge, MA: Harvard University Press. https://doi.org/10.4159/harvard.9780674420106.

Mondada, L. (2018). Multiple temporalities of language and body in interaction: Challenges for transcribing multimodality. Research on Language and Social Interaction, 51(1), 85-106.

Mori, J. (2002). Task design, plan, and development of talk-in-interaction: An analysis of a small group activity in a Japanese language classroom. Applied Linguistics, 23, 323-347. 

L2. Acquisition et Interaction En Langue Etrangère (AILE), 21(1), 123-166.

Pekarek Doehler, S., \& Berger, E. (2018). L2 interactional competence as increased ability for context-sensitive conduct: A longitudinal study of story-openings. Applied Linguistics, 39(4), 555-578. https://doi.org/10.1093/applin/amw021

Pillet-Shore, D. (2012). Greeting: Displaying stance through prosodic recipient design. Research on Language and Social Interaction, 45(4), 375-398.

Relampagos, B. (2019). Lx speaker acquisition of discourse markers: Pragmatic competence over time. Unpublished ms.

Sacks, H. (1992). Lectures on conversation. v. 1-2. Oxford: Blackwell.

Schegloff, E. A. (1968). Sequencing in conversational openings. American Anthropologist, 70, 1075-1095.

Sert, O. (2019). The interplay between collaborative turn sequences and active listenership: Implications for the development of L2 interactional competence. In M. R. Salaberry \& S. Kunitz (Eds.), Teaching and testing L2 interactional competence: Bridging theory and practice (pp. 142-166). New York: Routledge.

Svennevig, J. (1999). Getting acquainted in conversation : A study of initial interactions. Amsterdam: John Benjamins.

Webb, H., vom Lehn, D., Heath, C., Gibson, W., Evans, B. J. W. (2013). The problem with "problems": The case of openings in optometry consultations. Research on Language and Social Interaction, 46(1), 65-83.

Young, R. (1996). Form-function relations in articles in English interlanguage. In R. Bayley \& D. R. Preston (Eds.), Second language acquisition and linguistic variation (pp. 135-175). Amsterdam: John Benjamins.

Transcription conventions (derived from Jefferson, 2004 and Mondada, 2018)

[ ] left and right brackets indicates the start and end of overlapping talk

$=\quad$ equal sign indicates latched talk (no natural break)

(0.5) numbers in parentheses time lapses in talk. Less than 2 tenths of a second is indicated with (.)

Lovely $\quad$ underlining indicates stress

Lo::vely colons indicate sound stretches

$\downarrow \uparrow \quad$ up and down arrows indicate pitch shifts upper case indicates talk that is louder relative to the surrounding talk

${ }^{\circ}$ go away $\quad$ words enclosed in degree signs indicate softer talk

\# cross hatch sign around words indicates creaky voice 
$-$

$?$

;

$<>$

$><$

-hhh

hhh

$w r(h) d$

$(1)$

(lovely)

((sneeze)) dash indicates a sound cut off by a glottal stop

a question mark indicates final high rising intonation

the semicolon indicates rising intonation but not as high as the question mark

the comma indicates continuing intonation

the period/full stop indicates final falling intonation

words inside the outward pointing angle brackets are for slower talk

words inside the inward pointing angle brackets are for faster talk

indicates and audible in breath

indicates and audible out breath

an $(h)$ in the middle of the word indicate laughter token

empty parentheses indicates transcriber is unsure of what was spoken

words inside parentheses indicates the transcriber's best guess at what was uttered

Non verbal behavior by participants is indicated in lighter font below the transcribed words. The lower case letter is for the identification of the participant doing the non verbal behavior. The placement of the non verbal behavior relative to the talk is indicated by typographic symbols that are not part of the transcription system $(\wedge, *,+, \%$ etc) 
1

2

3

John Hellermann is a Professor in Applied Linguistics at Portland State University, Portland, Oregon (USA). Using methods from conversation analysis, he has investigated the sequential actions and practices in language learning. He is also interested in the prosodic organization or language and the linguistic landscapes of urban areas.

Yo-An Lee is a faculty member of the English Department at Sogang University in Seoul, South Korea. Informed by ethnomethodology and conversation analysis, his research concerns face-to-face interactions, classroom discourse, qualitative ethnography, and composition. He has published work in Modern Language Journal, Applied Linguistics, Journal of Pragmatics, and Discourse Processes. His current projects include nonnative discourse, lecturing sequences, and composition studies. 